\title{
Erysipelas of the upper extremity: About 25 cases of breast cancer with loco regional therapy
}

\author{
Saadani $\mathrm{CH}^{*}$, Baybay H, Zinoune S, Douhi $Z$ and Mernissi FZ \\ Department of Dermatology, Hassan II hospital, Fes, Morocco
}

\begin{abstract}
Aim: The aim of this study was to evaluate the prevalence of erysipelas of the upper extremity in women treated for breast cancer.

Methods: A study of 7-years retro-prospective study identifying 25 cases of erysipelas of the upper extremity following treatment for breast cancer; was carried out between March 2010 and December 2017 at the Hassan II hospital Fes, Morroco, we describe the clinical, therapeutic, and evolutionary aspects.

Results: The mean age was of 48,17 years. All patients had a breast surgery and lymphadenectomy. The erysipelas appeared with an average of 5.23 years after cancer treatment and was recurrent in seven cases. Lymphedema occurred in eighteen patients. The clinical aspect was an inflammatory plaque. The portal of entry was found in $73.91 \%$ of patients. The upper limb was affected in all cases. Involvement of the axillary folds or the chest was observed in $30.43 \%$. Treatment with amoxicillin associated with clavulanic acid was undertaken for all patients.
\end{abstract}

Conclusion:_Lymphadenectomy and radiotherapy in breast cancer may lead to lymphedema, which can be evident or sometimes discrete. Those patients who developed erysipelas in our series usually fared well with treatment, but many had recurrences attributed to persistent lymphedema.

\section{Introduction}

Erysipelas is a distinct type of superficial cutaneous cellulitis with marked dermal lymphatic vessel involvement caused by group A beta hemolytic streptococcus, rarely caused by S. aureus [1]. Lymphedema, venous stasis, web intertrigo, and obesity are risk factors in the adult patient [2]. Erysipelas of the upper extremity in women treated for breast cancer is relatively known but rarely reported. Malignancy and local impairment of venous and lymphatic circulation are reported to be predisposing factors. We attempted to characterize the clinical and evolutionary characteristics of erysipelas after treatment of breast cancer.

\section{Materials and methods}

Our study was a retro-prospective analysis of 255 patients with erysipelas observed during the period from march 2010 until December 2017 at the department of dermatology at Hassan II Hospital Fes, Morocco, we identify 25 cases of erysipelas of the upper limb following treatment for breast cancer.

The clinical data were collected from the files of the hospitalized patients.

For each patient we recorded the age, past medical history, clinical findings, laboratory finds, treatment, and outcome.

\section{Results}

The age of our patients ranged between 31 and 75 years with a mean age of 48.17 years. All our patients had undergone mastectomy and lymphadenectomy for breast cancer, 12 had chemotherapy, and 20 had radiotherapy. History of obesity was found in 7 patients, diabetes in 6. Lymphedema was noted in thirteen patients.
The erysipelas appeared with an average of 5.23 years after cancer treatment ( 3 months to 15 years) and was recurrent in 7 cases, the number of episodes varied from 1 to 3 .

The portal of entry was found in $73.91 \%$, with (post traumatic wound: $8.69 \%$; interdigital tinea: $13.03 \%$, under breast :13.03\%), mastectomy scar :13.03\%).

The site of involvement was the homolateral superior limb for all the cases. Involvement of the axillary folds or the chest was observed in $30.43 \%$ (Figure 1). The clinical aspect was an inflammatory plaque in all cases. It was complicated by purpura in three case (Figure 2), blisters in $26.03 \%$.

Laboratory abnormalities included increased white blood cell count (with predominance of segmented neutrophils) in fifteen cases; the white count was normal in eight cases, and the CRP was increased in twenty cases. The score of Laboratory Risk Indicator for Necrotizing Fasciitis (LRINEC) was $>6$ in 5 cases.

Outcome was favorable. All patients were treated with intravenous amoxicillin associated with clavulanic acid $(50 \mathrm{mg} / \mathrm{kg} /$ day). Once the patients became afebrile and otherwise had a marked improvement, the route of penicillin administration was changed to oral. The duration of treatment varied between 6 and 30 days with an average of 16 days. Prevention with benzyl penicillin was initiated in $44.82 \%$ of patients.

${ }^{*}$ Correspondence to: Saadani CH, Department of Dermatology, Hassan II hospital, Fes, Morocco, E-mail: ch.saadani@gmail.com

Received: August 01, 2018; Accepted: August 20, 2018; Published: August 23, 2018 


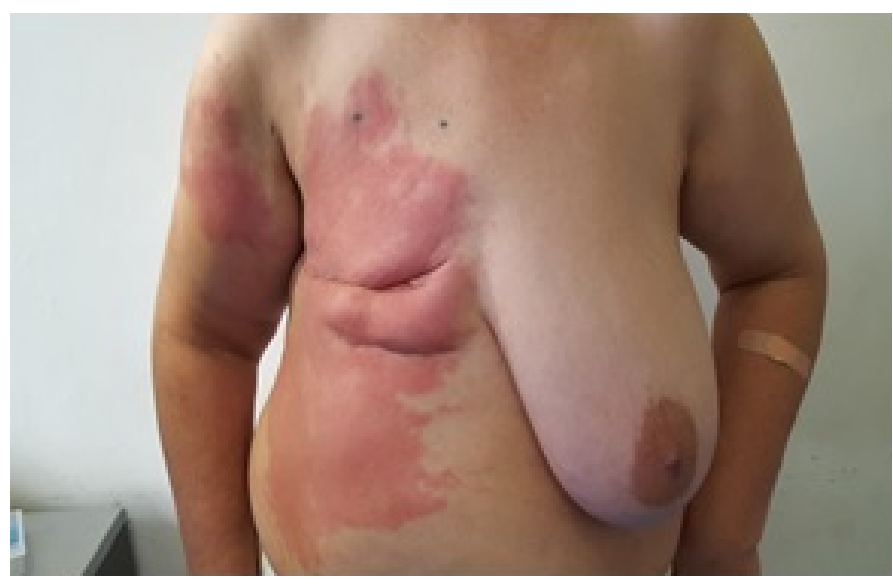

Figure 1. Involvement of the axillary folds and the chest

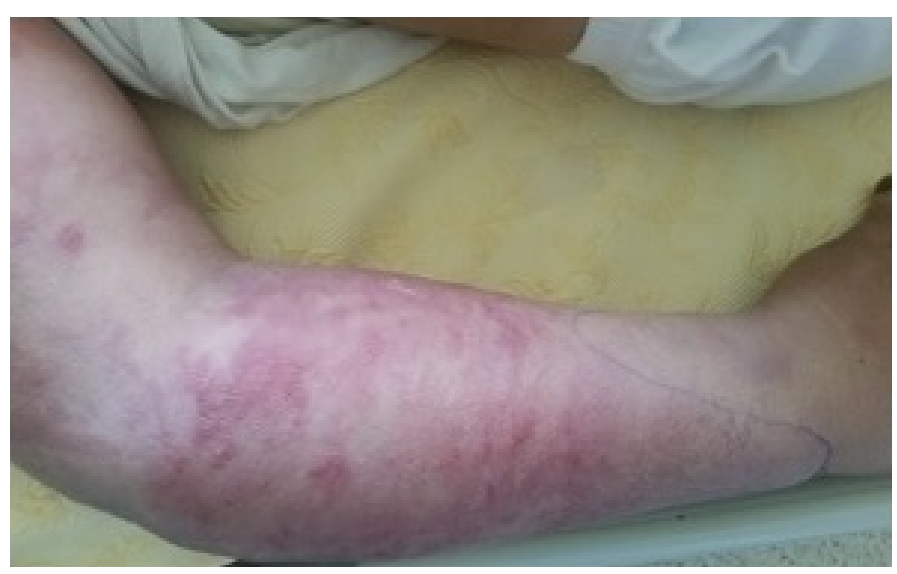

Figure 2. Erythema, edema and purpura of the forearm and arm

\section{Discussion}

Erysipelas is a dermohypodermal infection that most often occur the face or lower extremity. However, localization at the upper extremity and at the thoracic level remains infrequent. Mastectomy and radiotherapy for breast cancer are factors contributing to this complication, but few cases are reported in the literature [3].

The lymphatic circulation is affected by the radiotherapy and mastectomy favoring the obstruction and the progressive destruction of lymphatic communications, hence the lymphedema [4]. This lymphatic stasis appeared to play an important role in the occurrence of erysipelas in our patients.

Other factors that may play a role in developing infection in areas of lymphedema include diabetes which was noted in six of our patients, obesity, treatment with corticosteroids, and immune suppression. Once lymphedema is established, the affected arm is subject to erysipelas developing from minor infections such as paronychia, folliculitis, and interdigital web-space infection, as reported in our patients, such infections would not be significant in the normal arm.

Lymphedema following lymph-node dissection for invasive breast cancers is common and its impact on long-term quality of life in survivors of early-stage breast cancer should not be underestimated $[5,6]$.

The risk of lymphedema correlates with the use of postoperative radiotherapy and the number of lymph nodes removed [3].
The diagnosis of erysipelas is essentially clinical, a fever of acute onset with a sharply demarcated, warm, indurated and painful erythema.

The principal antibiotic recommended for treating $\beta$-hemolytic streptococci infection, including S. pyogenes, is penicillin G [7]. When administered orally, penicillin $\mathrm{V}$ is used; however, because that drug isn't available in our hospital, amoxicillin, sometimes associated with clavulanic acid, another oral penicillin, is used.

Penicillin G is the treatment of choice, but we used amoxicillin associated with clavulanic acid given its availability in our hospital. Following the acute phase, the treatment may be given by oral routes. The outcome is generally favorable.

In addition to antibiotics, scrupulous personal hygiene may be beneficial because group-A Streptococci may colonize unbroken skin [8].

The major late complication of this erysipelas is more lymphedema, which favors recurrence of infection. Each recurrence may do further local damage to lymphatic channels and thus perpetuate a vicious cycle. For patients who have recurrent erysipelas, antibiotic prophylaxis (especially with benzathine-benzylpenicillin or phenoxymethlpenicillin) is recommended [9]. The eradication of every portal of entry is recommended, especially for Local fungal infection of the skin or nails.

\section{Conclusion}

The occurrence of erysipelas following treatment of breast cancer correlates with the associated lymphedema. The treatment is an antibiotic during the acute phase of the disease and eventually an antibioprophylaxis to avoid recurrences. Attention should be given to measures that prevent lymphedema and eradicate potential portals of entry.

\section{References}

1. Naveena KN, Paia VV, Soria T, Kalabhavib S (2012) Erysipelas after breast cancer treatment. The Breast 21: $218 \mathrm{e} 219$.

2. Saavedra A, Weinberg AN, Swartz MN, Johnson RA (2008) Soft-tissue infections: Erysipelas, cellulitis, ganrgenous ceilulitis, and myonecrosis. In: Wolff K, Goldsmith LA, Katz SI, Gilchrest BA, Paller AS, et al. (Edtrs). Fitzpatrick's dermatology in general medicine. ( $7^{\text {th }}$ edn). New York: McGraw-Hill: 1720e4.

3. Masmoudi A, Maaloul I, Turki H, Elloumi Y, Marrekchi S, et al. () Erysipelas after breast cancer treatment (26 cases). Dermatology Online J 11: 12. [Crossref]

4. de Godoy JMP, Azoubel LMO, de Fátima M, Godoy MDG (2009) Erysipelas and lymphangitis in patients undergoing lymphedema treatment after breast-cancer therapy. Acta Dermatoven APA 18.

5. Fredriksson I, Liljegren G, Arnesson LG, Emdin SO, Palm-Sjövall M, et al. (2002) Consequences of axillary recurrence after conservative breast surgery. Br J Surg 89: 902-908. [Crossref]

6. Voogd AC, Ververs JM, Vingerhoets AJ, Roumen RM, Coebergh JW, et al. (2003) Lymphoedema and reduced shoulder function as indicators of quality of life after axillary lymph node dissection for invasive breast cancer. Br J Surg 90: 76-81. [Crossref]

7. Kwak YG, Choi SH, Kim T, Park SY, Seo SH, et al. (2017) Clinical Guidelines for the Antibiotic Treatment for Community-Acquired Skin and Soft Tissue Infection. Infect Chemother 49: 301-325. [Crossref]

8. Herman C, Hamdy M (1984) Recurrent streptococcal cellulitis complicating radial hysterectomy and radiation. Obstet Gynecol 63: 862-864. [Crossref]

9. Sjoblom AC, Eriksson B, Jorup-Ronstrom C, Karkkonen K, Lindqvist M (1993) Antibiotic prophylaxis in recurrent erysipelas. Infection 21: 390-393. [Crossref]

Copyright: (C2018 Saadani $\mathrm{CH}$. This is an open-access article distributed under the terms of the Creative Commons Attribution License, which permits unrestricted use, distribution, and reproduction in any medium, provided the original author and source are credited. 